\title{
Uso e qualidade da água subterrânea para irrigação no Semi-Árido piauiense ${ }^{1}$
}

Aderson S. de Andrade Júnior ${ }^{2}$, Ênio F. de F. e Silva ${ }^{3}$, Edson A. Bastos ${ }^{2}$, Francisco de B. Melo ${ }^{2}$ Clarice M. Leal ${ }^{2}$

\section{RESUMO}

A região semi-árida do Estado do Piauí é caracterizada por baixa intensidade pluviométrica e elevadas taxas de evapotranspiração. Porém a reserva de água subterrânea torna possível o desenvolvimento de atividades antrópicas, potencializada, na maioria dos casos, pelas características hidrogeológicas do subsolo, que permitem explotações de alta vazão de água com boa qualidade; todavia, alguns poços atingem formações de baixa vazão e qualidade de água com concentração de sais elevada e que, se utilizada para irrigação, pode ocasionar a salinização e a sodificação dos solos. Dessa forma, objetivou-se caracterizar as formas de uso e a qualidade das águas subterrâneas em parte da região semi-árida do Piauí, visando ao seu uso para irrigação. Coletaram-se amostras em 225 poços distribuídos espacialmente, nas quais foram analisadas as seguintes variáveis: condutividade elétrica, sódio, cálcio, magnésio, relação de adsorção de sódio, carbonato, bicarbonato, cloreto e sulfato. Em relação ao uso da água, predominou o uso doméstico (53,61\%), seguido pela irrigação $(21,17 \%)$, com os seguintes métodos: gotejamento (14,03\%); microaspersão (3,83\%); aspersão convencional (16,11\%); canhão e autopropelido (13,66\%); superfície $(16,76 \%)$ e outros métodos artesanais $(35,52 \%)$. Os mapas de classes de risco de uso para irrigação, gerados a partir da qualidade da água subterrânea, evidenciam a ocorrência de sub-áreas com as seguintes classes: nenhuma restrição, moderada restrição e severa restrição.

Palavras-chave: salinidade, qualidade de água, hidrogeologia, aqüífero Serra Grande

\section{Use and quality of groundwater for irrigation in semi-arid region of the Piauí State, Brazil}

\begin{abstract}
The semi-arid region in the State of Piauí, Brazil, is characterized by low rain fall and high evapotranspiration. However, the groundwater reserves make possible the economic development by underground hydrogeology characteristics, which allow extractions of high water flow with good quality, in most of the cases. However, some wells reached formations that have low discharge and water with high salt concentration, which if used for irrigation may cause salinization and sodification. The main goal of this work was to characterize the different uses and quality of groundwater in a part of the semi-arid area of Piauí, with a view to its use for irrigation. Samples were collected in 225 wells distributed spatially in the area, in which the following variables were analyzed: electrical conductivity, $\mathrm{Na}, \mathrm{Ca}, \mathrm{Mg}, \mathrm{SAR}, \mathrm{CO}_{3}, \mathrm{HCO}_{3}, \mathrm{Cl}$ and $\mathrm{SO}_{4}$. Regarding water use, the domestic use prevailed $(53.61 \%)$, followed by irrigation $(21.17 \%)$, with the following irrigation methods: drip irrigation $(14.03 \%)$; microsprinkler (3.83\%); conventional sprinkler (16.11\%); gun sprinkler and traveler irrigation machine (13.66\%); surface irrigation $(16.76 \%)$ and other handmade methods $(35.52 \%)$. The maps of classes of use risk irrigation generated from groundwater quality showed the occurrence of sub-areas with the following classes: no restriction, moderate restriction and severe restriction.
\end{abstract}

Key words: salinity, water quality, hydrogeology, Serra Grande aquifer

1 Projeto de pesquisa financiado com recursos do Instituto do Milênio do Semi-Árido - CNPq

2 Embrapa Meio-Norte, Av. Duque de Caxias, 5650. CP 01. CEP 64006-220. Teresina, PI. Fone: (86) 225-1141. Fax: (86) 225-1142.

E-mail: aderson@cpamn.embrapa.br; edson@cpamn.embrapa.br; brito@cpamn.embrapa.br; clarice@cpamn.embrapa.br.

${ }^{3}$ Departamento de Tecnologia Rural, UFRPE, CEP 52171-900. Recife. E-mail: enio.silva@dtr.ufrpe.br 


\section{INTRODUÇÃO}

A região sudeste do Piauí caracteriza-se como de clima semi-árido, onde a quantidade de chuvas é escassa e de forma concentrada. Neste cenário, a agricultura irrigada surge como alternativa para a sustentabilidade econômica da atividade agrícola. Em função das características climáticas e geológicas da região (de origem sedimentar), a água subterrânea constitui importante forma de reserva hídrica.

O conhecimento da qualidade da água subterrânea, relativa à concentração salina, torna-se ferramenta necessária ao planejamento da exploração desse recurso e ao manejo empregado, caso esta água se destine à irrigação. Segundo Ayers \& Westcot (1985), a água utilizada na irrigação, mesmo que com baixos níveis de salinidade, pode acarretar um processo de salinização, caso não seja manejada corretamente. De acordo com Oliveira (1997), cerca de 30 milhões de hectares irrigados no mundo se encontram severamente afetados por sais.

Cruz \& Melo (1969) citam que, no Nordeste, o clima (pluviometria), características no armazenamento das águas (aqüíferos livres, confinados ou fraturas) e natureza geológica (influência litológica na composição química da água) são os principais fatores que interferem no processo de salinização causada pelo uso das águas subterrâneas.

Na região semi-árida do Piauí predominam basicamente três formações sedimentares, denominadas de Cabeça, Pimenteira e Serra Grande, dispostas nesta ordem sobre o embasamento cristalino. Dependendo da formação geológica que o poço tubular explora, aspectos químicos relacionados à qualidade de água para irrigação podem variar bastante, ou seja, podese encontrar água com baixíssimas concentrações iônicas até águas extremamente salinas (CPRM, 1999). Por exemplo, poços que atingem a formação Serra Grande possibilitam a extração de água com condutividade elétrica abaixo de $0,5 \mathrm{dS}$ $\mathrm{m}^{-1}$, enquanto poços que exploram águas armazenadas em fraturas do cristalino podem apresentar água com condutividade elétrica acima de $15 \mathrm{dS} \mathrm{m}^{-1}$.

Torna-se difícil definir uma classificação para a água de irrigação que possa ser utilizada em qualquer condição ou em qualquer localização geográfica. Os riscos a serem considerados quando se avalia a adequabilidade de determinada água para irrigação são principalmente os riscos de salinização, sodificação e alcalinização por carbonatos para o solo; aspectos tóxicos em relação a cloretos e sódio para as plantas e prejuízos ao sistema de irrigação pela alta concentração de sais de baixa solubilidade (FAO/UNESCO, 1973).

O aumento da porcentagem de sódio trocável (PST) do solo pela adsorção do sódio presente na água de irrigação é um importante fator a ser considerado. A PST é a propriedade do solo que melhor se correlaciona com os efeitos do sódio na permeabilidade do solo e efeitos tóxicos deste íon nas plantas, porém visto que a relação de adsorção de sódio (RAS) do solo é uma boa estimativa da PST, esta tem sido utilizada para se avaliar os riscos de sodicidade (Richards, 1954). A RAS da água de irrigação pode ser utilizada como medida do risco de sodicidade, visto que ela pode ser correlacionada com a RAS do solo, depois de atingido o equilíbrio dinâmico.
Entretanto, a classificação da água de irrigação de acordo com o risco de problemas de infilltração de água no solo, deve estar baseada na RAS e na condutividade elétrica da água de irrigação (CEa), levando-se em conta que, quanto maior a salinidade da água menor será o efeito dispersante do sódio, uma vez que os sais atuam no solo de maneira oposta ao sódio, ou seja, os sais presentes na solução do solo têm efeito floculante, aumentando a infiltração (Ayers \& Westcot, 1985).

O teor de sais em águas subterrâneas depende de sua origem, do curso sobre o qual ela flui e da composição e facilidade de dissolução do substrato em que se encontra em contato (Yaron, 1973), ou seja, da geologia da região (Shalhevet \& Kamburov, 1976). Os valores de $\mathrm{pH}$ tendem a ser mais altos quando ocorre a presença de bicarbonatos na água (Hermes \& Silva, 2002). Elevados teores de carbonato e bicarbonato na água, quando utilizada para irrigação, podem promover a precipitação de cálcio, na forma de carbonato de cálcio, facilitando um suposto processo de sodificação do solo (Ayers \& Westcot, 1985).

Realizou-se este trabalho com o objetivo de levantar-se as características qualitativas das águas subterrâneas em parte da região semi-árida do Estado do Piauí, avaliando-se a possibilidade do seu uso para irrigação, e determinar a porcentagem de poços onde o uso de água para irrigação é prioritário, destacando-se os métodos utilizados.

\section{MATERIAL E MÉTODOS}

O estudo foi realizado em parte da região semi-árida do Estado do Piauí, localizada entre as latitudes $06^{\circ} 30^{\prime} 00^{\prime \prime}$ e $07^{\circ}$ $58^{\prime} 00^{\prime \prime} \mathrm{S}$ e as longitudes $40^{\circ} 22^{\prime} 00^{\prime \prime}$ e $41^{\circ} 48^{\prime} 00^{\prime \prime} \mathrm{W}$. A Figura 1 ilustra a área do levantamento, destacando-se os 29 municípios integrantes, correspondendo a um total de 13.856,31 $\mathrm{km}^{2}$ (IBGE, 2002). Em parte da área estudada ocorre a maior zona de influência na recarga do aqüífero Serra Grande, que se destaca pela elevada exploração para diferentes fins, dentre eles, a irrigação.

Os poços existentes na área do estudo foram cadastrados, inventariados e georreferenciados por intermédio de GPS de navegação, verificando-se a presença de 2.165 poços. As informações levantadas foram dispostas em questionário próprio, contendo: as posições geográficas dos poços, as informações referentes às características construtivas, as características hidrogeológicas, de uso atual e ambiental das fontes de água e de seu entorno. Nos casos em que a irrigação era o uso prioritário, inventariou-se, também, o método de irrigação utilizado, apresentando-se o resultado de forma descritiva através de gráficos.

Com base nas informações dos poços e por meio de análise de agrupamento, selecionaram-se 225 poços, a serem avaliados em relação à qualidade físico-química da água, sendo 45 poços para cada grupo homogêneo, distribuídos espacialmente, de modo a cobrir toda a área em estudo.

Os 225 poços avaliados foram visitados em outubro e novembro de 2003 (estação seca), em aproximadamente duas semanas. A determinação da qualidade de água de cada poço foi efetuada no local, por meio de sondas portáteis e uma 


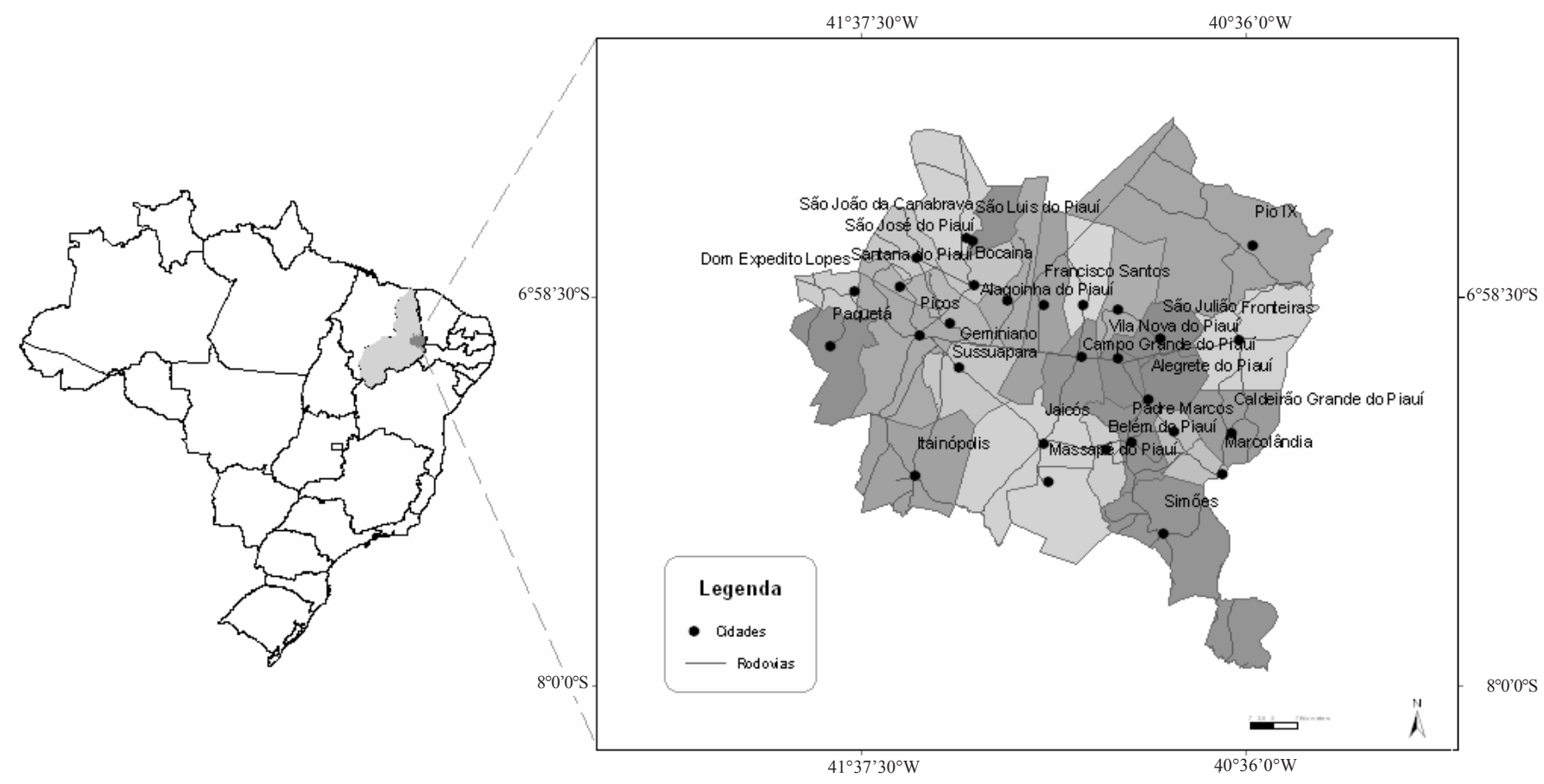

Figura 1. Localização da área e divisão política dos municípios inseridos na região em estudo.

amostra de água de cada poço foi coletada para posterior análise em laboratório. As amostras coletadas corresponderam ao volume de $1 \mathrm{~L}$, sendo acondicionadas em recipientes plásticos, observando-se o detalhe de preencher todo o recipiente, de modo a se evitarem alterações na relação carbonato/bicarbonato.

Foram determinadas em campo as seguintes variáveis: condutividade elétrica (CE) e pH por intermédio de uma sonda YSI modelo 9600; em laboratório determinaram-se os seguintes íons: sódio $(\mathrm{Na})$, cálcio $(\mathrm{Ca})$, magnésio $(\mathrm{Mg})$, cloreto $(\mathrm{Cl})$, carbonato $\left(\mathrm{CO}_{3}\right)$, bicarbonato $\left(\mathrm{HCO}_{3}\right)$ e sulfato $\left(\mathrm{SO}_{4}\right)$ de acordo com a metodologia proposta pela EMBRAPA (1997).

Com base na concentração desses íons, estimaram-se os valores de carbonato de sódio residual (CSR) proposto por Eaton (1949) e a relação de adsorção de sódio (RAS) apresentada por Yaron (1973), modelos apresentados respectivamente nas Eq. 1 e 2.

$$
\mathrm{CSR}=\left(\mathrm{CO}_{3}+\mathrm{HCO}_{3}\right)(\mathrm{Ca}+\mathrm{Mg})
$$

sendo as concentrações de $\mathrm{CO}_{3}, \mathrm{HCO}_{3}, \mathrm{Ca}, \mathrm{Mg}$ na água expressas em mmol $_{\mathrm{c}} \mathrm{L}^{-1}$.

$$
\mathrm{RAS}=\frac{\mathrm{Na}}{\sqrt{\frac{\mathrm{Ca}+\mathrm{Mg}}{2}}}
$$

em que as concentrações de $\mathrm{Na}, \mathrm{Ca}$ e $\mathrm{Mg}$ na água foram expressas em $\mathrm{mmol}_{\mathrm{c}} \mathrm{L}^{-1}$.

Em um sistema de informações geográficas (SIG), os mapas temáticos das variáveis analisadas foram gerados, sendo utilizada a "krigeagem" como interpolador. Definiram-se áreas com três classes de restrição de uso de água: nenhuma restrição, moderada restrição e severa restrição, cujos limites estão explícitos nas Tabelas 1 e 2 . As classes de restrição de uso para irrigação consideram o risco de sodificação do solo, combinando a RAS e a CE da água de irrigação, visando evitar problemas de infiltração da água com posterior processo de sodificação do solo, segundo Ayers \& Westcot (1985). Por meio de tabulação cruzada, gerou-se um mapa para indicar as

Tabela 1. Classes de restrição de uso da água para irrigação de acordo com a qualidade

\begin{tabular}{lccc}
\hline \multirow{2}{*}{ Variáveis } & \multicolumn{3}{c}{ Classes de Restrição de Uso para Irrigação } \\
\cline { 2 - 4 } & Nenhuma & Moderada & Severa \\
$\mathrm{CE}\left(\mathrm{dS} \mathrm{m}^{-1}\right)$ & $<0,7$ & 0,7 a 3,0 & $>3,0$ \\
$\mathrm{Na}\left(\mathrm{mmol}_{\mathrm{c}} \mathrm{L}^{-1}\right)$ & $<3,0$ & $>3,0$ & - \\
$\mathrm{Ca}+\mathrm{Mg}_{\left(\mathrm{mmol}_{\mathrm{C}} \mathrm{L}^{-1}\right)}$ & $<5,0$ & $5,0 \mathrm{a} 15,0$ & $>15,0^{*}$ \\
$\mathrm{CO}_{3}\left(\mathrm{mmol}_{\mathrm{c}} \mathrm{L}^{-1}\right)$ & $<0,1$ & $0,1 \mathrm{a} 0,2$ & $>0,2^{*}$ \\
$\mathrm{HCO}_{3}\left(\mathrm{mmol}_{\mathrm{c}} \mathrm{L}^{-1}\right)$ & $<1,5$ & $1,5 \mathrm{a} 8,5$ & $>8,5$ \\
$\mathrm{Cl}_{\left(\mathrm{mmol}_{\mathrm{c}} \mathrm{L}^{-1}\right)}$ & $<3,0$ & $>3,0$ & - \\
$\mathrm{SO}_{4}\left(\mathrm{mmol}_{\mathrm{c}} \mathrm{L}^{-1}\right)$ & $<10$ & $10 \mathrm{a} 30$ & $>30^{\star}$ \\
$\mathrm{CSR}\left(\mathrm{mmol}_{\mathrm{c}} \mathrm{L}^{-1}\right)$ & $<1,25$ & $1,25 \mathrm{a} 2,5$ & $>2,5$ \\
\hline
\end{tabular}

Fonte: Ayers \& Westcot (1985)

Tabela 2. Classes de restrição de uso de água para irrigação de acordo com a relação de adsorção de sódio (RAS)

\begin{tabular}{cccc}
\hline \multirow{2}{*}{ RAS } & \multicolumn{3}{c}{ Classes de Restrição de Uso para Irrigação } \\
\cline { 2 - 4 } & Nenhuma & $\begin{array}{c}\text { Moderada } \\
\text { Condutividade elétrica }\left(\mathbf{d S ~ m}^{-1} \text { ) }\right.\end{array}$ \\
0 a 3 & $>0,7$ & 0,7 a 0,2 & $<0,2$ \\
3 a 6 & $>1,2$ & 1,2 a 0,3 & $<0,3$ \\
6 a 12 & $>1,9$ & 1,9 a 0,5 & $<0,5$ \\
12 a 20 & $>2,9$ & 2,9 a 1,3 & $<1,3$ \\
20 a 40 & $>5,0$ & 5,0 a 2,9 & $<2,9$ \\
\hline
\end{tabular}

R. Bras. Eng. Agríc. Ambiental, v.10, n.4, p.873-880, 2006. 
áreas que possuem águas subterrâneas com características combinadas de CE e RAS possíveis de serem utilizadas.

\section{RESULTADOS E DISCUSSÃO}

Os valores porcentuais referentes ao uso das águas explotadas do subsolo da região estudada estão ilustrados na Figura 2. Ressalta-se que em mais da metade dos poços $(53,61 \%)$ a água retirada é usada em atividades de subsistência, de caráter doméstico, ou seja, são poços particulares ou explorados por pequenas comunidades, na maioria dos casos por intermédio de chafarizes; em seqüência, em $21,17 \%$ dos poços, o uso primordial é a irrigação. O abastecimento de zonas urbanas é responsável por $16,57 \%$ dos poços e apenas 7,53\% do total dos poços se destina ao uso na atividade pecuária, visando principalmente a dessedentação de animais. Outras atividades também são referenciadas, correspondendo a $1,11 \%$ dos poços; por exemplo, o uso com finalidade industrial, com $0,10 \%$, representando apenas duas unidades.

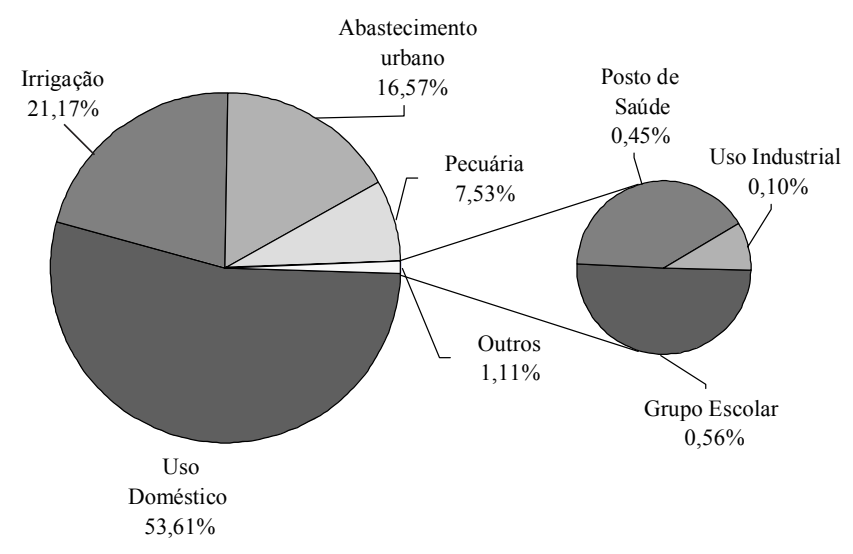

Figura 2. Múltiplos usos das águas explotadas do aqüífero Serra Grande na área em estudo

Nos poços cadastrados, os métodos de irrigação observados foram: o gotejamento, com 14,03\%; a microaspersão, com 3,83\%; a aspersão convencional, com $16,11 \%$; canhão e autopropelido, com 13,66\%; irrigação por superfície, com $16,76 \%$ e outros métodos artesanais com $35,52 \%$ (Figura 3 ). Dentre o grupo de outros métodos artesanais, foram identificados regadores manuais, mangueiras, tubos de bambu perfurado, dentre outros.Em mais da metade dos poços utilizados para irrigação, os métodos utilizados (por superfície + artesanais) apresentam, na maioria dos casos, baixa eficiência de aplicação da água. A implementação de métodos de irrigação mais eficientes e de manejo de água adequados pode ser considerada ferramenta eficiente na economia de água, além de possibilitar um controle maior do processo de salinização (Bernardo, 1996).

As áreas que apresentam nenhuma restrição, moderada restrição e severa restrição ao uso da água para irrigação, considerando-se a condutividade elétrica da água subterrânea, encontram-se apresentadas na Figura 4A. A região enquadrada na classe com severa restrição para o uso de irrigação, com

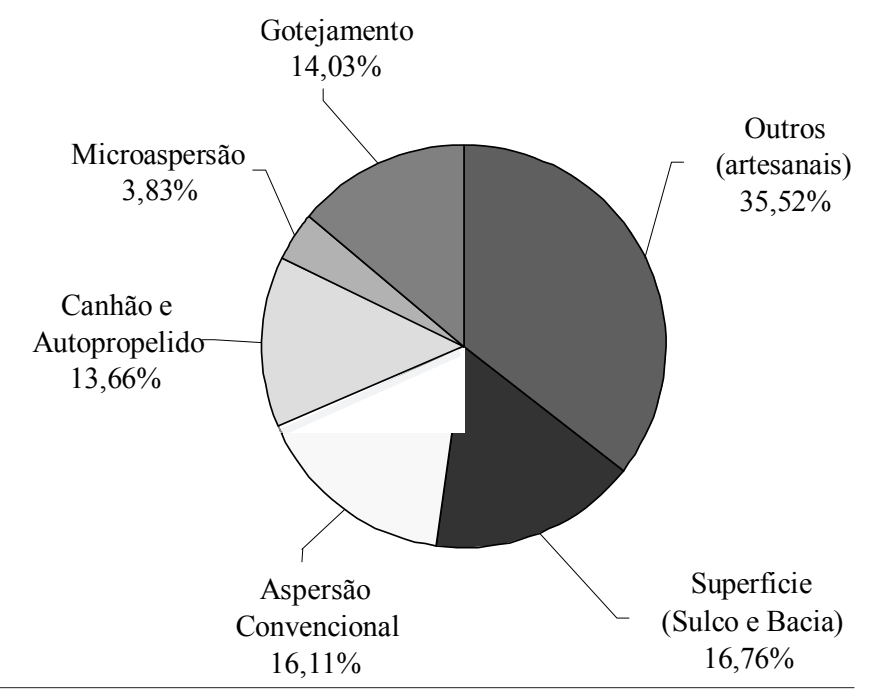

Figura 3. Métodos de irrigação utilizados com água proveniente dos poços cadastrados na área em estudo

condutividade elétrica (CE) acima de $3 \mathrm{dS} \mathrm{m}^{-1}$, acham-se ao sul da área em estudo e corresponde ao município de Simões. Geologicamente a região se encontra sobre o embasamento cristalino, onde os poços existentes, embora em pequena quantidade, retiram água reservada em raras fraturas; portanto, além da qualidade inapropriada para irrigação, o potencial de vazão inviabiliza a irrigação, sob qualquer aspecto.

Nas áreas classificadas como de moderada restrição, com CE entre 0,7 e $3 \mathrm{dS} \mathrm{m}^{-1}$, o uso da água para irrigação é dependente de técnicas específicas de manejo da irrigação, tais como as apresentadas por Medeiros \& Gheyi (1997), que possibilitam um balanço de sais desejado na zona radicular, a partir de aplicações de lâminas de lixiviação. As regiões com moderada restrição correspondem a aproximadamente metade da área de estudo (Figura 4A) e parte a leste, onde os poços atingem fraturas do embasamento cristalino ou de formações sedimentares que sofrem influência do cristalino, enquanto que a sudoeste, nos municípios de Itainópolis, Paquetá e Picos, onde a maioria dos poços analisados atinge a Formação Pimenteira, na qual a água apresenta certa concentração de sais (CPRM, 1999). Representada pelo tom de cor mais claro, está a área onde a água subterrânea possui valores de CE abaixo de $0,7 \mathrm{dS} \mathrm{m}^{-1}$, ou seja, onde não existe nenhuma restrição do uso para irrigação. Nesta região, os poços analisados extraem água da Formação Serra Grande, a qual possui excelentes características químicas de baixa concentração de sais e de alta vazão (Figura 4A).

Os maiores valores de condutividade elétrica (CE) estão presentes na porção leste da área estudada, cujo fato condiz com a formação geológica da região, ou seja, os valores de CE maiores que $1,20 \mathrm{dS} \mathrm{m}^{-1}$ estão representados na mesma porção onde se encontra o afloramento do cristalino, mostrando forte interferência da geologia sobre a qualidade da água subterrânea (Shalhevet \& Kamburov, 1976). Corroborando com esses resultados, Santiago et al. (1999), em estudo realizado em Picos, encontraram valores de $2,5 \mathrm{dS} \mathrm{m}^{-1}$ a $25^{\circ} \mathrm{C}$, evidenciando que essas águas têm restrição para as atividades agrícolas, em virtude do risco de salinização dos solos, 
A

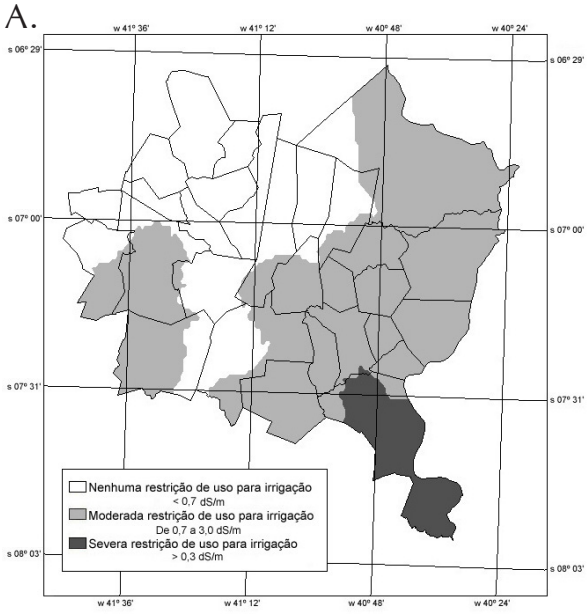

B.

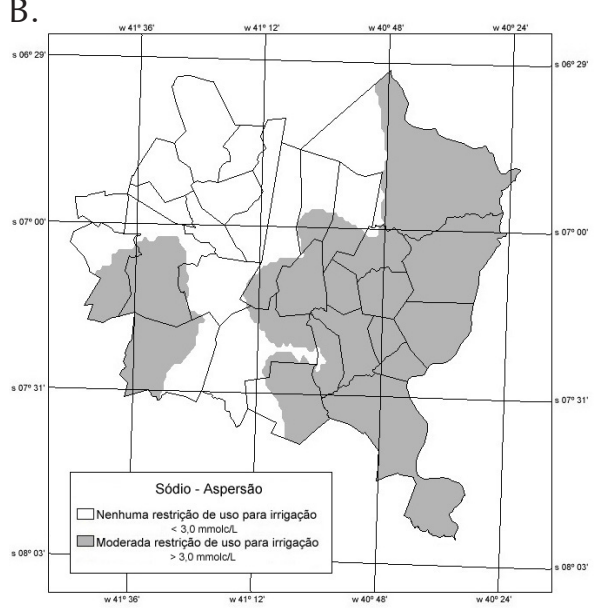

C.

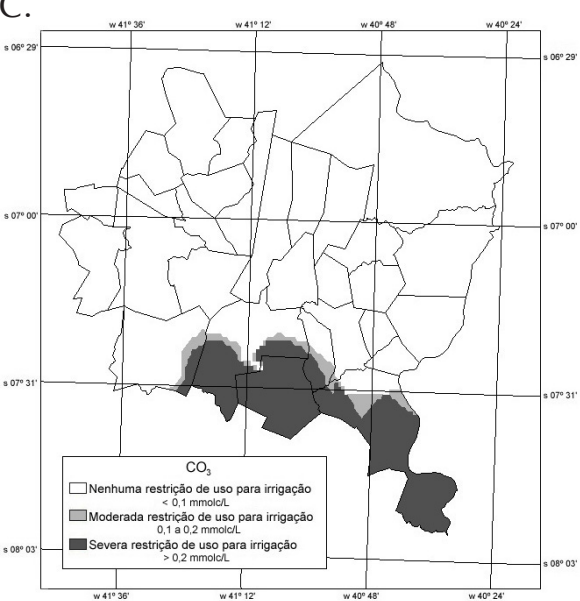

D.

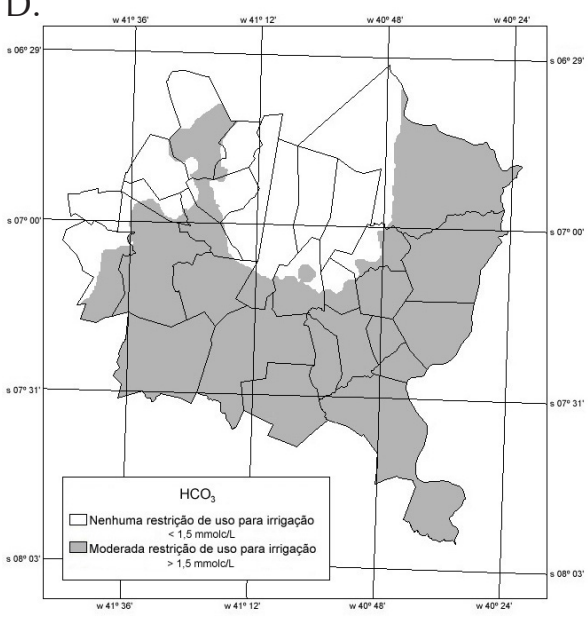

E.

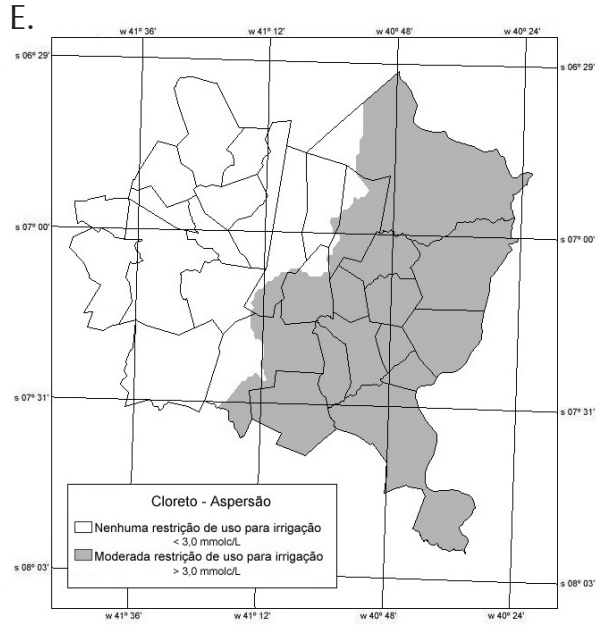

F.

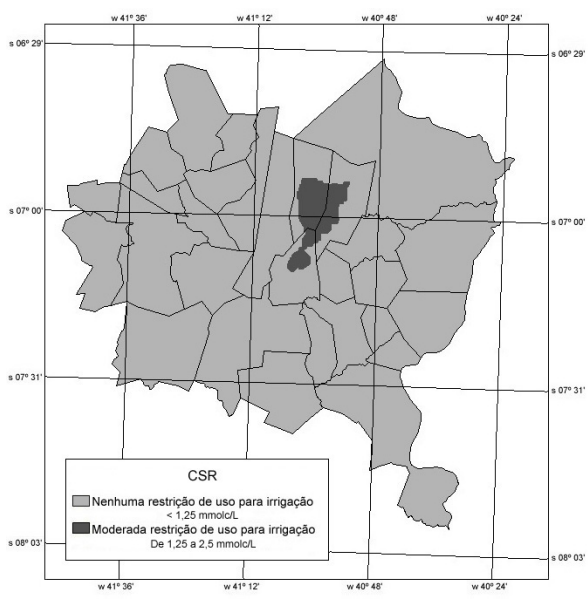

Figura 4. Classes de restrição do uso da água subterrânea para irrigação com base na CE (A), concentração de sódio (B); concentração de carbonato (C); concentração de bicarbonato (d); na concentração de cloreto (E) e no carbonato de sódio residual (F).

porém, os mesmos autores descrevem que ocorre progressiva redução na salinidade das águas, em direção ao interior da bacia, isto é, nas porções confinadas do aqüífero Serra Grande. Na região a leste de Picos, composta pelos municípios de Pio IX, Caldeirão do Piauí, Fronteiras, Marcolândia, Simões, São Julião, Alegrete, Francisco Macedo, Padre Marcos, Belém do Piauí, Vila Nova do Piauí e parte dos municípios de Campo Grande e Alagoinhas, as águas analisadas apresentaram valores de CE superiores a $1,2 \mathrm{dS} \mathrm{m}^{-1}$, sugerindo que sua utilização para irrigação seja acompanhada de técnicas de controle do processo de salinização. Algumas áreas, como a parte mais a sudeste de Pio IX e o município de São Julião, valores acima de $3,0 \mathrm{dS} \mathrm{m} \mathrm{m}^{-1}$ são encontrados, restringindo o seu uso para irrigação.

Conforme a Figura 5A, o pH da água dos poços da região variou de 6,4 a 8 , valores que não restringem seu uso para irrigação. Ayers \& Westcot (1985) citam que uma faixa normal de pH está compreendida entre valores de 6,5 a 8,4; todavia, Nakayama (1982) cita que não existe restrição para águas com pH abaixo de 7, com restrição moderada para águas com pH entre 7 e 8 e com severa restrição para pH acima de 8 , em relação à obstrução de emissores para irrigação localizada.

Quanto a concentração de sódio na água subterrânea, os valores determinados e geoespacializados estão ilustrados na
Figura 4B. As regiões representadas pela coloração mais escura possuem concentrações que apresentam moderada restrição ao uso da água subterrânea para irrigação, em relação à toxidez nas plantas, principalmente de culturas com maior sensibilidade. Os limites utilizados de $3,0 \mathrm{mmol}_{\mathrm{c}} \mathrm{L}^{-1}$ são referentes à irrigação por aspersão (Ayers \& Westcot, 1985), em que a toxidez passa a ser potencializada pela oportunidade do aumento na absorção via folhas.

A concentração de cálcio + magnésio na água subterrânea da região estudada (Figura 5B) mostra-se de forma elevada, principalmente na região onde a geologia corresponde ao afloramento cristalino. Desta forma, o efeito da concentração de sódio, no aspecto de sodificação do solo, passa a ser minimizada. Os valores encontrados de $\mathrm{Ca}+\mathrm{Mg}$ não superam os limites preconizados por Ayers \& Westcot (1985), que é de $20 \mathrm{mmol}_{\mathrm{c}} \mathrm{L}^{-1}$ para cálcio e $5 \mathrm{mmol}_{\mathrm{c}} \mathrm{L}^{-1}$ para o magnésio; entretanto, deve-se ter cuidado especial na área mais a leste, em relação ao entupimento de emissores para irrigação localizada, quando a água apresentar concentrações elevadas de carbonato e bicarbonato.

A concentração de $\mathrm{CO}_{3}$ e de $\mathrm{HCO}_{3}$ na água subterrânea utilizada para irrigação refere-se a parâmetros importantes na avaliação do risco de sodificação do solo, visto que esses ânions, quando combinados com o cátion cálcio, formam o 

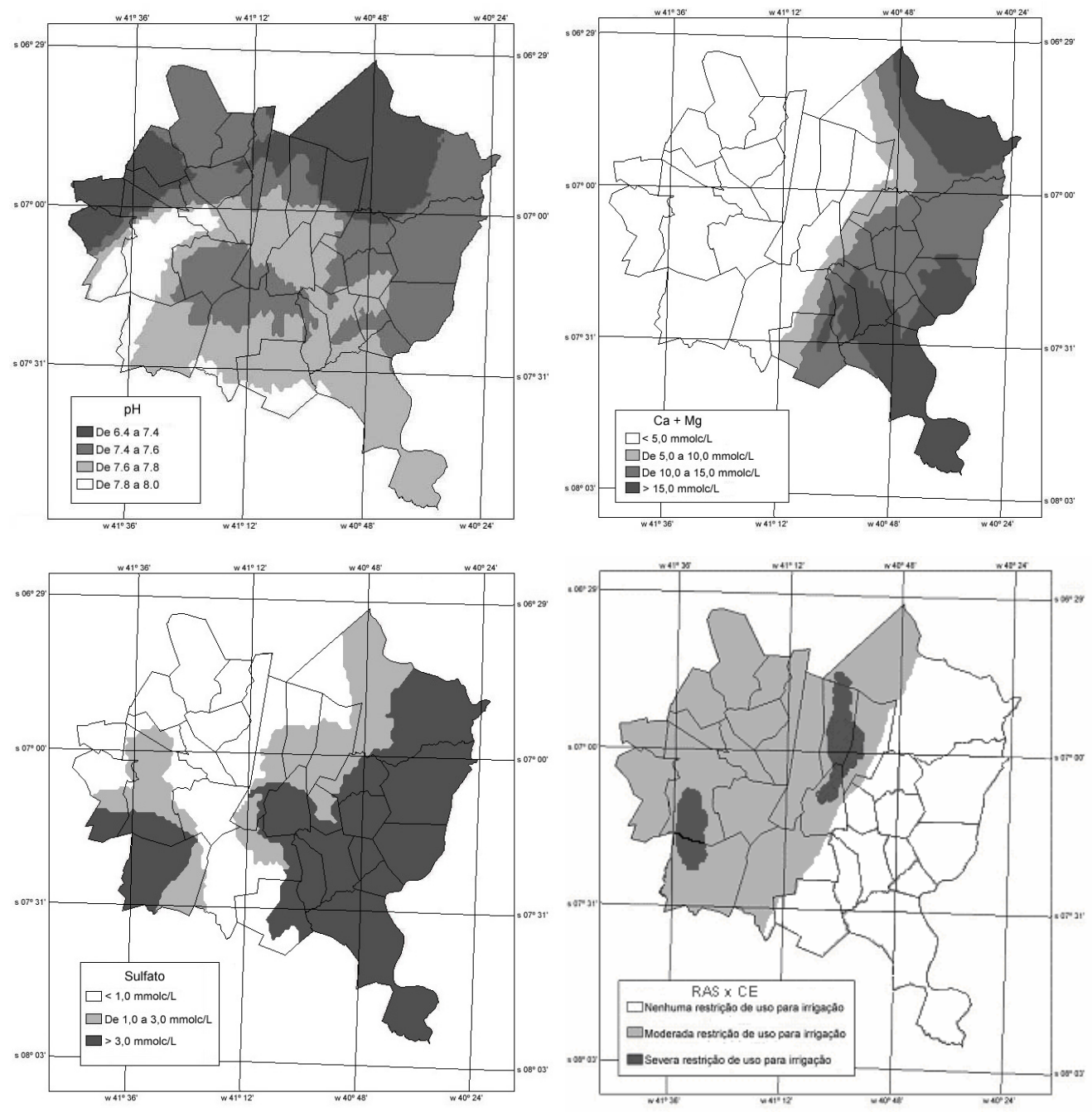

Figura 5. Potencial hidrogeniônico (A), concentração de cálcio + magnésio (B), concentração de sulfato (C) e classe de restrição do uso para irrigação com base na relação de adsorção de sódio e condutividade elétrica (D)

carbonato de cálcio, sal de baixa solubilidade (Yaron, 1973). Desta forma, a precipitação do carbonato de cálcio retira da solução parte do cálcio, interferindo na relação de adsorção de sódio. Na área estudada, apenas uma pequena região localizada ao sul, compreendendo os municípios de Simões e Massapê do Piauí e parte dos municípios de Jaicós e Belém do Piauí, se enquadra dentro das classes com moderada e severa restrição de uso da água para irrigação, cuja concentração de carbonato apresenta valores superiores a 0,1 mmol $_{\mathrm{c}} \mathrm{L}^{-1}$ (Figuras $4 \mathrm{C}$ e $4 \mathrm{D}$ ).

Em 72,3 \% da área em estudo, a concentração de bicarbonato na água subterrânea está acima de $1,5 \mathrm{mmol}_{\mathrm{c}} \mathrm{L}^{-1}$, ou seja, com moderada restrição ao uso da água para irrigação (Figura 4D); entretanto, em grande parte da área com concentração de bicarbonato superior a $1,5 \mathrm{mmol}_{\mathrm{c}} \mathrm{L}^{-1}$ a concentração de cálcio + magnésio na água subterrânea apresenta valores acima de 5,0 $\mathrm{mmol}_{\mathrm{c}} \mathrm{L}^{-1}$ (Figura 5B). Na região estudada, onde as concentrações de cálcio + magnésio presentes na água se apresentam mais baixas $\left(<5,0 \mathrm{mmol}_{\mathrm{c}} \mathrm{L}^{-1}\right)$ e as concentrações de sódio mais elevadas $\left(>3,0 \mathrm{mmol}_{\mathrm{c}} \mathrm{L}^{-1}\right)$ como em Itainópolis, Picos e Paquetá (Figura 4B), indica-se o monitoramento da relação de adsorção de sódio na solução do solo, em virtude da possibilidade de precipitação do cálcio e magnésio, utilizando-se corretivos sempre que necessário, como sugerido por Holanda \& Amorim (1997).

As concentrações de sulfato se encontram espacializadas na Figura 5C. Segundo os padrões de Ayers \& Westcot (1985), os valores medidos nas águas provenientes dos poços não atingiram concentrações que possam ser prejudiciais ao solo ou às plantas, mostrando-se inferiores ao limite de $20 \mathrm{mmol}_{\mathrm{c}} \mathrm{L}^{-1}$. As regiões com maiores concentrações de sulfato correspondem às mesmas regiões nas quais a concentração de sódio se mostrou mais elevada; todavia, os valores de cálcio e de magnésio compensam o sódio encontrado, estabilizando a relação de adsorção de sódio, enquanto as concentrações de sulfato encontradas não são suficientes para promover a precipitação do cálcio na forma de sulfato de cálcio. Na Figura $4 \mathrm{E}$ acham-se representadas as áreas com diferentes classes de restrição do uso da água subterrânea para irrigação, utilizando-se sistemas de aspersão. A região com cor mais clara não mostra qualquer restrição de uso, enquanto a região mais escura tem concentração de cloreto que pode resultar em toxidez às culturas mais sensíveis. Conforme Ayers \& Wes- 
tcot (1985), a irrigação por aspersão favorece a absorção de cloreto pela folhas, potencializando o problema; por sua vez a Figura 4F mostra o mapa temático com as classes de restrição de uso da água subterrânea para irrigação, com base no carbonato de sódio residual (CSR). Na maioria dos municípios, os valores encontrados ficaram abaixo de $1,25 \mathrm{mmol}_{\mathrm{c}} \mathrm{L}^{-1}$, demonstrando que a qualidade da água é adequada para a prática da irrigação, sendo baixo o risco de impermeabilização do solo. Valores acima de $2,5 \mathrm{mmol}_{\mathrm{c}} \mathrm{L}^{-1}$ de CSR, indicariam que a qualidade de água seria imprópria para irrigação, fato não constatado. Caso fossem observadas áreas com concentração superior a 2,5 mmol $_{\mathrm{c}} \mathrm{L}^{-1}$ na água, adotar-se-iam medidas no sentido de viabilizar seu uso na irrigação, como a aplicação de corretivos aliados a um manejo de água adequado. Nas áreas com valores de CSR intermediários (valores entre 1,25 e 2,5 mmol $_{\mathrm{c}} \mathrm{L}^{-1}$ ), a água subterrânea na região estudada para fins de irrigação, deve ser usada com cautela e mediante monitoramento constante das conseqüências do seu uso sobre o solo.

O risco de sodificação não pode ser avaliado apenas pela concentração de sódio presente na água; tem-se de observar a relação entre este parâmetro e a concentração de cálcio e magnésio, representado pela relação de adsorção de sódio (RAS); além disso, outros fatores podem interferir no processo, como a concentração de ânions capazes de reagir com o cálcio, formando sais de baixa solubilidade, precipitando o cálcio e alterando a RAS; outro aspecto importante e que se deve levar em conta, é que o fato de, quanto maior a salinidade da água, menor será o efeito dispersante do sódio, uma vez que os sais atuam no solo de maneira oposta ao sódio, ou seja, os sais presentes na solução do solo têm efeito floculante, aumentando a infiltração e reduzindo o risco de sodificação.

$\mathrm{Na}$ Figura 5D visualizam-se as áreas com as classes de restrição do uso da água subterrânea para irrigação, com base na relação de adsorção de sódio e condutividade elétrica. Parte da área representada pela coloração mais clara, localizada sobre o embasamento cristalino, não apresenta risco de sodificação pela utilização da água subterrânea para irrigação, visto que os valores de condutividade elétrica determinados nessa região compensam os valores encontrados para a relação de adsorção de sódio, possibilitando aumento na infiltração da água no solo. A região do mapa representado pelo tom de cinza intermediário apresenta moderada restrição de uso para irrigação em virtude da baixa condutividade elétrica da água subterrânea, que poderá ocasionar efeito dispersivo em alguns tipos de solos argilosos, principalmente onde a argila predominante seja expansiva. Nessa região, sugere-se o monitoramento da porcentagem de sódio trocável no solo, bem como o uso de técnicas que venham minimizar o processo. As manchas escuras delimitam os locais onde as características químicas associadas à concentração eletrolítica da água subterrânea inferem elevado perigo de sodificação do solo, não sendo recomendado o uso da água subterrânea para irrigação. Essas manchas escuras estão localizadas nos municípios de Itainópolis, Picos, Alagoinha, Campo Grande do Piauí, Alagoinha do Piauí e Monsenhor Hipólito.

\section{CONCLUSÕES}

1. As atividades de subsistência, de caráter doméstico, constituem o principal uso em $53,61 \%$ dos poços. A irrigação corresponde ao segundo uso preponderante, em $21,17 \%$ dos poços; em $35,52 \%$ dos poços analisados usam-se métodos de irrigação artesanais, que apresentam baixa eficiência de aplicação de água.

2. A porção leste da área em estudo apresenta maior número de parâmetros, que restringem severamente o uso de água subterrânea para irrigação, locais onde os poços exploram água de fraturas presentes no embasamento cristalino. Na parte mais central da região, a excelente qualidade de água, extraída por poços que atingem a Formação Serra Grande, permite o uso da água subterrânea para irrigação, sem maiores conseqüências sobre a salinização e sodificação do solo.

\section{LITERATURA CITADA}

Ayers, R.S.; Westcot, D.W. Water quality for agriculture. Roma: FAO, 1985. 174 p. Irrigation and Drainage Paper, 29, Rev. 1.

Bernardo, S. Manual de irrigação. 6 ed. Viçosa: Imprensa Universitária, 1996. 657p.

CPRM. Projeto hidrogeológico do Piaú II - bases municipais/ perfil hidrogeológico do município de Picos. Série Hidrogeologia - informações básicas, v.24. Teresina: CPRM, 1999. $32 \mathrm{p}$.

Cruz, W.B.; Melo, F.A.C.F. de. Zoneamento químico e salinização das águas subterrâneas do Nordeste do Brasil. Boletim de Recursos Naturais, Recife. v.7, n.1/4, p.7-40, 1969.

FAO/UNESCO. Irrigation, drainage and salinity: an international source book. Paris: UNESCO/Hutchinson, 1973. p.177205.

Eaton, F.M. Significance of carbonates in irrigation waters. Soil Science, Baltimore, v.60, p.123-133, 1949.

EMBRAPA - Empresa Brasileira de Pesquisa Agropecuária. Serviço Nacional de Levantamento e Conservação do Solo. Manual de métodos de análise de solo. 2.ed. Rio de Janeiro: Embrapa Solos. 1997. 212p.

Hermes, L.C.; Silva, A.S. Parâmetros básicos para avaliação da qualidade das águas: análise e seu significado ambiental. Jaguariúna: Embrapa Meio Ambiente, 2002. 32p.

Holanda, J.S.; Amorim, J.R.A. Qualidade da água para irrigação. In: Gheyi, H.R.; Queiroz; J.E.; Medeiros, J.F. Manejo e controle da salinidade na agricultura irrigada. Campina Grande: UFPB, 1997. p.137-169. 
IBGE - Instituto Brasileiro de Geografia e Estatística. Base de informações municipai. 3.ed. Rio de Janeiro: IBGE, 2002. CDRom

Medeiros, J.F.; Gheyi, H.R. Manejo do sistema solo-água-planta em solos afetados por sais. In: Gheyi, H.R.; Queiroz, J.E.; Medeiros, J.F. Manejo e controle da salinidade na agricultura irrigada. Campina Grande: UFPB, 1997. p.239-287.

Nakayama, F. S. Water analysis and treatment techniques to control emitter plugging. In: Pro. Irrigation Association Conference, Portland, Oregon. 1982.

Oliveira, M. Gênese, classificação e extensão de solos afetados por sais. In: Gheyi, H.R.; Queiroz; J.E.; Medeiros, J.F. Manejo e controle da salinidade na agricultura irrigada. Campina Grande: UFPB, 1997. p.1-35.
Richards, L.A. (ed.) Diagnosis and improvement of saline and alkali soils. Washington: United States Salinity Laboratory, 1954. 160 p. Agriculture Handbook, 60.

Santiago, M.M.F.; Batista, J.R; Frischkorn, H; Batista, J.R.X.J; Mendes Filho, J.; Santiago, R.S. Mudanças na composição química das águas subterrâneas do município de Picos-PI. In: Simpósio Brasileiro de Recursos Hídricos, 13, 1999, Belo Horizonte. Anais.... Belo Horizonte: ABRH (CD-Rom). 1999. Shalhevet, J.; Kamburov, J. Irrigation and salinity: A worldwide survey. New Delhi: International Commission on Irrigation and Drainage, 1976. 106p.

Yaron, B. Water suitability for irrigation. In: Yaron, E.; Danfors, E.; Vaadid, Y. (eds.). Arid zone irrigation. Berlin: SpringlerVerlag, 1973. p.71-85. Ecological Studies, 5 